\title{
PROPRIEDADES FÍSICAS DE UM CAMBISSOLO HÚMICO AFETADAS PELO TIPO DE MANEJO DO SOLO
}

\author{
Ildegardis Bertol'1,3*; Josué Fernando Beutler ${ }^{1,3}$; Dirceu Leite ${ }^{2,4}$; Odair Batistela ${ }^{2,4}$ \\ ${ }_{2}^{1}$ CAV/UDESC, C.P. 281 - CEP: 88520-000 - Lages, SC. \\ ${ }_{3}^{2}$ Graduandos da Faculdade de Agronomia - CAV/UDESC. \\ ${ }^{3}$ Bolsista CNPq \\ ${ }^{4}$ Bolsistas PIBIC/CNPq \\ *Autor correspondente <a2ib@cav.udesc.br>
}

\begin{abstract}
RESUMO: A degradação das propriedades físicas do solo é um dos principais processos responsáveis pelo aumento da erosão hídrica. O preparo convencional predispõe o solo a este processo, já que é executado com intenso revolvimento mecânico do solo. A semeadura direta, por outro lado, é um sistema de manejo conservacionista, pois a ausência de preparo mantém os resíduos vegetais e aumenta o teor de matéria orgânica na superfície, apesar de aumentar a densidade e diminuir a porosidade superficial do solo. $O$ trabalho foi desenvolvido num CAMBISSOLO HÚMICO Alumínico, em Lages- SC, de maio de 1995 a novembro de 1999, com o objetivo de avaliar as modificações em algumas propriedades físicas do solo afetadas pelo manejo. Os tratamentos foram, preparo convencional executado com uma aração+duas gradagens (PCO) e semeadura direta (SDI), ambos com quatro repetições, além de um tratamento de campo nativo pastejado (CNP), com duas repetições. Na SDI foram cultivadas ervilhaca e milho em sucessão e, no PCO, adotou-se a sucessão milho seguido de pousio. Foram avaliadas a resistência do solo ao penetrômetro e diâmetro médio ponderado de agregados (DMP), ambos nas profundidades de $0-2,5 ; 2,5-5,0 ; 5,0-10,0$ e 10,0-15,0 cm, e a taxa de infiltração de água no solo. O tipo de manejo não afetou o DMP na camada de $0-2,5 \mathrm{~cm}$; nas demais camadas, no entanto, o CNP e SDI apresentaram valores maiores do que o PCO, não diferindo entre si. A resistência do solo ao penetrômetro foi maior na SDI do que nos demais tratamentos, na camada de 0-2,5 cm. A taxa de infiltração de água no solo, tanto inicial quanto final, foi maior no PCO do que nos demais tratamentos. Palavras-chave: preparo conservacionista, resistência do solo, estabilidade de agregados, infiltração de água
\end{abstract}

\section{PHYSICAL PROPERTIES OF AN HAPLUMBREPT AS AFFECTED BY SOIL MANAGEMENT}

\begin{abstract}
Physical degradation of soils favors water erosion. Because of its intensity, conventional tillage usually acellerates the soil erosion process. Therefore, no-tillage is considered a soil conservation management system, because it preserves crop residues on soil surface. However, no-tillage may also increase bulk density and decrease surface soil total porosity. This study investigates the effects of soil management on a Haplumbrept, from May 1995 to November 1999, in the region of Lages, SC, Brazil. Three soil tillage treatments were used: conventional tillage (plowing plus disking), no-tillage and natural pasture. The crop sequences used were maize and vetch in the no-tillage system, and maize and fallow in the conventional tillage system. -Soil strength and mean weight diameter of soil aggregates (MWD) were evaluated for soil layers of 0-2.5 cm, 2.5-5.0 cm, 5.0-10.0 cm and 10.0-15.0 cm. Soil water intake rate was also evaluated. The MWD did not differ betwen treatments for the $0-2.5 \mathrm{~cm}$ layer; in the other layers the soil presented higher values for the natural pasture and no-tillage treatments. Soil strength was higher for the no-tillage treatment in the $0-2.5 \mathrm{~cm}$ layer. The water intake rate was higher in the soil of the conventional tillage as compared to other management treatments.
\end{abstract}

Key words: conservation tillage, soil strength, aggregates stability, water intake

\section{INTRODUÇÃO}

A degradação das propriedades físicas do solo é um dos principais processos responsáveis pela perda da qualidade estrutural e aumento da erosão hídrica. Algumas práticas de manejo do solo e das culturas provocam alterações nas referidas propriedades, principalmente na sua estrutura, podendo tais alterações serem permanentes ou temporárias. Alterações de propriedades físicas do solo podem manifestar-se de várias maneiras, influenciando o desenvolvimento das plantas. Assim, o solo submetido ao cultivo tende a perder a estrutura original, pelo fracionamento dos agregados em unidades menores, com conseqüente redução no volume de macroporos e aumentos no volume de microporos e na densidade do solo (Tisdall \& Oades, 1980; Carpenedo \& Mielniczuk, 1990).

O sistema de preparo convencional, em geral, promove um intenso revolvimento do solo na camada superficial, o que pode favorecer a decomposição da matéria orgânica, ocasionando considerável efeito prejudicial na qualidade estrutural do solo. A presença de camadas compactadas em subsuperfície, nesses sistemas de manejo, reflete uma degradação estrutural, 
com aumento da densidade e reduções do tamanho médio dos agregados, volume e tamanho dos macroporos, taxa final de infiltração de água e desenvolvimento radicular das plantas (Dalla Rosa, 1981; Silva \& Mielniczuk, 1997).

Em solos intensamente cultivados pelos preparos convencionais, o surgimento de camadas compactadas, com redução do volume de macroporos e aumento de microporos, determina uma diminuição do volume de poros ocupado pelo ar e um aumento na retenção de água (Dalla Rosa, 1981; Bertol \& Santos, 1995). Em decorrência disso, observa-se uma diminuição da taxa de infiltração de água no solo, com conseqüente aumento das taxas de escoamento superficial e de erosão hídrica (Bertol et al., 1997; Schick et al., 2000). A redução na taxa de infiltração de água no solo é a propriedade que melhor reflete o grau de degradação do sistema poroso do solo (Dalla Rosa, 1981).

A adoção de sistemas de manejo sem revolvimento do solo e a manutenção de resíduos vegetais na superfície, favorecem o contínuo aporte de carbono orgânico, o que é fundamental para a manutenção de uma estrutura de boa qualidade (Carpenedo \& Mielniczuk, 1990). Assim, a semeadura direta apresenta-se como um sistema de manejo conservacionista do solo, pois, além de não revolver 0 solo, mantém os resíduos vegetais na superfície, preservando e/ou aumentando o teor de matéria orgânica (Bayer \& Mielniczuk, 1997; Castro Filho et al., 1998), apesar de aumentar a densidade e reduzir a porosidade superficial (Bertol et al., 2000). Nesse sistema de manejo, o adensamento do solo na superfície, em decorrência da ausência de preparo, acarreta diminuição do volume de poros, especialmente de macroporos, o que implica num aumento da resistência do solo a penetração de raízes (Bertol, 1989) e, possivelmente, na estabilidade dos agregados e na infiltração de água no solo.

O objetivo do trabalho foi avaliar as alterações na estabilidade dos agregados em água, resistência do solo ao penetrômetro e taxa de infiltração de água, num Cambissolo Húmico alumínico submetido ao preparo convencional e à semeadura direta por quatro anos seguidos, bem como de um campo nativo pastejado.

\section{MATERIAL E MÉTODOS}

O trabalho foi desenvolvido no período de 1995 a 1999, no Centro de Ciências Agroveterinárias de Lages (SC), sobre um CAMBISSOLO HÚMICO Alumínico argiloso, com declividade média de $10 \%$, em parcelas experimentais com $100 \mathrm{~m}^{2}$ cada uma. Na camada de 0$15 \mathrm{~cm}$, o solo apresenta, em média, $42,1 \mathrm{~g} \mathrm{~kg}^{-1}$ de argila, $43,7 \mathrm{~g} \mathrm{~kg}^{-1}$ de silte e $14,2 \mathrm{~g} \mathrm{~kg}^{-1}$ de areia, com densidade de partículas de $2,69 \mathrm{~g} \mathrm{~cm}^{-3}$. Nas TABELAS 1 e 2 encontram-se algumas propriedades físicas e químicas, respectivamente, do solo estudado.
Os tratamentos de preparo de solo, em quatro repetições, foram o preparo convencional executado com uma aração+duas gradagens (PCO) e semeadura direta (SDI). No tratamento PCO cultivou-se milho na primavera-verão seguido de pousio no outono-inverno. O resíduo da parte aérea do milho foi removido da área experimental imediatamente após a colheita da cultura, permanecendo as soqueiras. No tratamento SDI, foram cultivados milho na primavera-verão e ervilhaca no outono-inverno, permanecendo os resíduos de ambas as culturas na superfície do solo. Estudou-se também um tratamento testemunha de campo nativo pastejado (CNP), em duas repetições.

Foram avaliadas a estabilidade dos agregados em água e a resistência do solo ao penetrômetro, ambos nas profundidades de $0-2,5 ; 2,5-5,0 ; 5,0-10,0 \mathrm{e}$ $10,0-15,0 \mathrm{~cm}$, e a taxa de infiltração de água no solo, em local escolhido aleatoriamente em cada parcela experimental.

As amostras para estabilidade de agregados em água, em número de 16 , foram coletadas com pá de corte quando o solo estava friável, destorroadas e embaladas em recipiente de plástico rígido. No laboratório, procedeu-se o peneiramento das amostras, com peneira de $8 \mathrm{~mm}$ de abertura da malha e, após secas à sombra por $72 \mathrm{~h}$, foram analisadas por peneiramento a úmido, seguindo 0 método proposto por Yoder (1936). O diâmetro médio ponderado dos agregados estáveis em água (DMP) foi calculado pelo método descrito por Kemper \& Chepil (1965).

As determinações de resistência do solo foram feitas com penetrômetro estático de bolso, com haste em forma de cone com $0,5 \mathrm{~cm}$ de diâmetro e escala variando de zero a $4,5 \mathrm{~kg} \mathrm{~cm}^{-2}$, em trincheiras com profundidade de $20 \mathrm{~cm}$ abertas com pá de corte. A haste do penetrômetro foi introduzida a $0,5 \mathrm{~cm}$ no solo. Sempre que o valor de resistência do solo ao penetrômetro ultrapassava o limite de sua escala, de $4,5 \mathrm{~kg} \mathrm{~cm}^{-2}$, o valor final era estimado, com base na avaliação quantitativa do comprimento da haste do penetrômetro efetivamente cravada no solo. Em cada uma das profundidades do solo acima referidas foram feitas 10 leituras de resistência do solo ao penetrômetro, totalizando 40 leituras em cada parcela experimental e 160 leituras no total de cada um dos tratamentos de SDI e PCO (quatro repetições). No PCN foram feitas 80 leituras dessa variável (duas repetições). A umidade do solo no momento dessas avaliações consta na TABELA 3.

A taxa de infiltração de água no solo foi avaliada durante duas horas, até leitura constante, utilizando-se cilíndricos concêntricos com carga hidráulica variável, conforme o método descrito por Forsythe (1975), em um ponto em cada parcela experimental, ou seja, quatro repetições nos tratamentos PCO e SDI e duas repetições no 
TABELA 1 - Algumas propriedades físicas, em diferentes profundidades (PROF), de um Cambissolo Húmico alumínico submetido a três sistemas de manejo do solo em Lages, SC

\begin{tabular}{lccccccccc}
\hline PROF & \multicolumn{3}{c}{$\mathrm{CNP}^{1}$} & \multicolumn{3}{c}{$\mathrm{PCO}^{2}$} & \multicolumn{3}{c}{$\mathrm{SDI}^{2}$} \\
\cline { 2 - 9 } & $\mathrm{CO}$ & $\mathrm{Ds}$ & $\mathrm{Ma}$ & $\mathrm{CO}$ & $\mathrm{Ds}^{3}$ & $\mathrm{Ma}^{3}$ & $\mathrm{CO}$ & $\mathrm{Ds}^{3}$ & $\mathrm{Ma}^{3}$ \\
\hline \multicolumn{1}{c}{$\mathrm{cm}$} & $\%$ & $\mathrm{~kg} \mathrm{dm}^{-3}$ & $\mathrm{dm}^{3} \mathrm{dm}^{-3}$ & $\%$ & $\mathrm{~kg} \mathrm{dm}^{-3}$ & $\mathrm{dm}^{3} \mathrm{dm}^{-3}$ & $\%$ & $\mathrm{~kg} \mathrm{dm}^{-3}$ & $\mathrm{dm}^{3} \mathrm{dm}^{-3}$ \\
$0,0-2,5$ & 3,59 & 1,00 & 0,34 & 2,37 & 1,06 & 0,33 & 3,28 & 1,39 & 0,13 \\
$2,5-5,0$ & 2,56 & 1,15 & 0,27 & 2,28 & 1,11 & 0,28 & 2,71 & 1,38 & 0,13 \\
$5,0-10,0$ & 2,49 & 1,22 & 0,10 & 2,29 & 1,24 & 0,09 & 2,64 & 1,25 & 0,18 \\
$10,0-15,0$ & 2,57 & 1,22 & 0,10 & 2,21 & 1,27 & 0,06 & 2,55 & 1,23 & 0,20 \\
Média & 2,80 & 1,15 & 0,20 & 2,29 & 1,17 & 0,19 & 2,80 & 1,31 & 0,16 \\
\hline
\end{tabular}

CNP: campo nativo pastejado; PCO: preparo convencional; SDI: semeadura direta; CO: carbono orgânico; Ds: densidade do solo; Ma: volume de macroporos.

${ }^{1}$ Média de duas repetições; ${ }^{2}$ média de quatro repetições.

${ }^{3}$ Resultados obtidos de Bertol et al. (2000).

TABELA 2 - Algumas propriedades químicas, em diferentes profundidades (PROF), de um Cambissolo Húmico alumínico submetido a três sistemas de manejo do solo em Lages, SC

\begin{tabular}{cccccccccc}
\hline PROF & \multicolumn{3}{c}{$\mathrm{CNP}^{1}$} & \multicolumn{3}{c}{$\mathrm{PCO}^{2}$} & \multicolumn{3}{c}{$\mathrm{SDI}^{2}$} \\
\cline { 2 - 10 } & $\mathrm{pH} \mathrm{H}_{2} \mathrm{O}$ & $\mathrm{P}$ & $\mathrm{K}$ & $\mathrm{pH} \mathrm{H}_{2} \mathrm{O}$ & $\mathrm{P}$ & $\mathrm{K}$ & $\mathrm{pH} \mathrm{H}_{2} \mathrm{O}$ & $\mathrm{P}$ & $\mathrm{K}$ \\
\hline \multicolumn{1}{c}{$\mathrm{cm}$} & $1: 1$ & $----\mathrm{mg} \mathrm{kg}^{-1}----$ & $1: 1$ & $----\mathrm{mg} \mathrm{kg}^{-1}---$ & $1: 1$ & $-----\mathrm{mg} \mathrm{kg}^{-1}-----$ \\
$0,0-2,5$ & 5,5 & 11,9 & 240 & 5,6 & 19,0 & 158 & 5,3 & 72,3 & 351 \\
$2,5-5,0$ & 5,5 & 8,9 & 166 & 5,6 & 20,9 & 131 & 5,5 & 28,7 & 243 \\
$5,0-10,0$ & 5,6 & 8,5 & 127 & 5,6 & 21,2 & 185 & 5,6 & 21,5 & 148 \\
$10,0-15,0$ & 5,8 & 6,2 & 97 & 5,7 & 24,1 & 106 & 5,8 & 18,5 & 163 \\
Média & 5,6 & 8,9 & 158 & 5,6 & 21,3 & 145 & 5,6 & 35,3 & 226 \\
\hline
\end{tabular}

CNP: campo nativo pastejado; PCO: preparo convencional; SDI: semeadura direta.

${ }^{1}$ Média de duas repetições; ${ }^{2}$ média de quatro repetições.

TABELA 3 - Valores médios da umidade do solo, em diferentes profundidades (PROF), num Cambissolo Húmico alumínico submetido a três sistemas de manejo do solo em Lages, SC

\begin{tabular}{|c|c|c|c|}
\hline PROF & $\mathrm{CNP}^{1}$ & $\mathrm{PCO}^{2}$ & SDR \\
\hline $\mathrm{cm}$ & \multicolumn{3}{|c|}{ 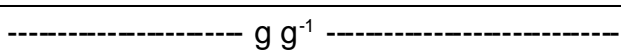 } \\
\hline $0,0-2,5$ & 0,228 & 0,239 & 0,215 \\
\hline $2,5-5,0$ & 0,241 & 0,241 & 0,229 \\
\hline $5,0-10,0$ & 0,240 & 0,240 & 0,227 \\
\hline $10,0-15,0$ & 0,239 & 0,240 & 0,226 \\
\hline Média & 0,237 & 0,240 & 0,224 \\
\hline
\end{tabular}

CNP: campo nativo pastejado; PCO: preparo convencional; SDI: semeadura direta.

${ }^{1}$ Média de duas repetições; ${ }^{2}$ média de quatro repetições.

tratamento CNP. A umidade do solo no momento dessas avaliações consta na TABELA 3. Os dados foram ajustados segundo o modelo de Philip (1957), ou seja: $\mathrm{i}=\mathrm{a} \mathrm{t}^{\mathrm{b}}+\mathrm{C}$, onde: $\mathrm{i}=$ taxa de infiltração de água no solo a ser estimada $\left(\mathrm{cm} \mathrm{h}^{-1}\right) ; \mathrm{t}=$ tempo $(\mathrm{h}) ; \mathrm{C}=$ taxa constante de infiltração de água no solo determinada $\left(\mathrm{cm} \mathrm{h}^{-1}\right) ; \mathrm{a}, \mathrm{b}=$ parâmetros de ajuste.

Os dados de estabilidade de agregados em água e de resistência do solo ao penetrômetro foram interpretados utilizando-se análise de variância e comparados pelo teste de Duncan a $5 \%$.

\section{RESULTADOS E DISCUSSÃO}

Os tratamentos não causaram diferença significativa no DMP, na profundidade de $0-2,5 \mathrm{~cm}$ (TABELA 4). No entanto, apesar dos valores de DMP não terem sido estatisticamente diferentes entre os tratamentos nessa profundidade, houve tendência de diminuição dessa variável no PCO, da ordem de $12 \%$, em relação à média da SDI e CNP. Nas demais profundidades, no entanto, a diferença do DMP entre os tratamentos foi estatisticamente significativa, sendo cerca de $20 \%$ menor no PCO do que na média dos demais sistemas de manejo. Isto pode ser explicado pelo revolvimento mecânico periódico do solo realizado no PCO e, também, pelo baixo aporte de matéria orgânica ao solo, nesse sistema de manejo (Bayer \& Mielniczuk, 1997; Bertol et al., 2000). A matéria orgânica é um poderoso agente de formação e estabilização dos agregados, sendo natural encontrar-se correlação positiva entre essas duas varáveis (Tisdall \& Oades, 1980; Castro Filho et al., 1998).

Houve tendência de aumento do DMP com a profundidade, nos tratamentos CNP e SDI, embora não estatisticamente diferentes, fato não observado no PCO (TABELA 4). Na média da SDI e CNP, a tendência de aumento dessa variável foi da ordem de $5 \%$, na camada de 5,0-15,0 cm, em relação à camada de $0-2,5 \mathrm{~cm}$. A 
falta de significância na diferença do DMP com a profundidade, pode estar relacionada com o período de tempo relativamente curto de condução do experimento, para que tal diferença seja expressa em maior magnitude.

Os valores de resistência do solo ao penetrômetro variaram entre tratamentos nas camadas de $0-2,5$ e 2,5 a $5,0 \mathrm{~cm}$ (TABELA 5). Na SDI, o valor foi aproximadamente 300 vezes maior do que no $\mathrm{PCO}$ e 4 vezes maior do que no CNP, na camada de $0-2,5 \mathrm{~cm}$. $\mathrm{Na}$ camada de 2,5-5,0 cm, essa variável foi $24 \%$ maior na SDI do que no PCO, não diferindo em relação ao CNP, concordando com dados obtidos por Dalla Rosa (1981). A densidade do solo não foi avaliada no presente estudo. No entanto, ela foi avaliada por Bertol et al. (2000) nesse mesmo experimento (TABELA 1), observando-se que ela foi maior na superfície do solo na SDI, o que concorda com Dalla Rosa (1981). Este comportamento foi influenciado principalmente pelo não revolvimento e pelo tráfico de máquinas e equipamentos sobre o solo, o que justifica os resultados da resistência

TABELA 4 - Valores médios do diâmetro médio ponderado de agregados estáveis em água, em diferentes profundidades (PROF), num Cambissolo Húmico alumínico submetido a três sistemas de manejo do solo em Lages, SC

\begin{tabular}{|c|c|c|c|}
\hline PROF & $\mathrm{CNP}^{1}$ & $\mathrm{PCO}^{2}$ & SDR \\
\hline $\mathrm{cm}$ & ----------- & $--\mathrm{mm}---$ & 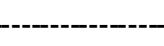 \\
\hline $0,0-2,5$ & $5,70 \mathrm{Aa}$ & 4,95 $\mathrm{Aa}$ & $5,60 \mathrm{Aa}$ \\
\hline $2,5-5,0$ & $6,15 \mathrm{Aa}$ & $4,68 \mathrm{Ba}$ & 5,82 Aa \\
\hline $5,0-10,0$ & $6,05 \mathrm{Aa}$ & $4,58 \mathrm{Ba}$ & 5,92 Aa \\
\hline $10,0-15,0$ & 6,05 Aa & 4,96 Ba & $5,74 \mathrm{ABa}$ \\
\hline Média & 5,99 & 4,79 & 5,77 \\
\hline
\end{tabular}

CNP: campo nativo pastejado; PCO: preparo convencional; SDI: semeadura direta.

Letras maiúsculas na linha e minúscula na coluna não diferem estatisticamente por Duncan a $5 \%$. Coeficiente de variação: $12 \%$. ${ }^{1}$ Média de duas repetições; ${ }^{2}$ média de quatro repetições.

TABELA 5 - Valores médios de resistência do solo ao penetrômetro, em diferentes profundidades (PROF), num Cambissolo Húmico alumínico submetido a três sistemas de manejo de solo em Lages, SC

\begin{tabular}{|c|c|c|c|}
\hline PROF & $\mathrm{CNP}^{1}$ & $\mathrm{PCO}^{2}$ & $S D I^{2}$ \\
\hline $\mathrm{cm}$ & --------- & $\mathrm{kg} \mathrm{cm}^{-2}$ & 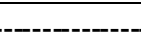 \\
\hline $0,0-2,5$ & $4,3 \mathrm{Ba}$ & $0,05 \mathrm{Ca}$ & $15,3 \mathrm{Aa}$ \\
\hline $2,5-5,0$ & $10,9 \mathrm{Aa}$ & $2,0 \mathrm{Ba}$ & 12,6 Aab \\
\hline $5,0-10,0$ & $8,4 \mathrm{Aa}$ & $2,7 \quad \mathrm{Aa}$ & $8,1 \mathrm{Aab}$ \\
\hline $10,0-15,0$ & 5,0 Aa & $3,7 \quad \mathrm{Aa}$ & $6,0 \mathrm{Ab}$ \\
\hline Média & 7,2 & 2,1 & 10,5 \\
\hline
\end{tabular}

CNP: campo nativo pastejado; PCO: preparo convencional; SDI: semeadura direta.

Letras maiúsculas na linha e minúscula na coluna não diferem estatisticamente, por Duncan a $5 \%$. Coeficiente de variação: $74 \%$. ${ }^{1}$ Média de duas repetições; ${ }^{2}$ média de quatro repetições do solo ao penetrômetro nesse sistema de manejo, nessa profundidade. Na camada de $5,0-15,0 \mathrm{~cm}$, o valor de resistência do solo ao penetrômetro não diferiu entre tratamentos, provavelmente em decorrência dos similares teores de umidade do solo (TABELA 3). Ainda, o período de tempo relativamente curto de condução do experimento pode ter sido insuficiente para que essa variável fosse afetada em maior profundidade. A não diferenciação nos valores de resistência do solo ao penetrômetro, nas camadas mais profundas do perfil, pode ser explicada, ainda, pela semelhança nos valores de densidade do solo (TABELA 1), constatada por Bertol et al. (2000) nesse experimento.

Os valores de resistência do solo ao penetrômetro no PCO foram muito baixos, especialmente aquele da camada de $0-2,5 \mathrm{~cm}$ (Figura 1), explicado pelo intenso revolvimento do solo na superfície e, também, pelos tratos culturais aplicados, como capinas manuais, os quais diminuíram a densidade do solo e aumentaram o volume de macroporos na superfície (TABELA 1). Ainda nesse tratamento, os valores de resistência do solo ao penetrômetro tenderam a aumentar com a profundidade do perfil, embora sem diferença estatística.

Os valores de resistência do solo ao penetrômetro foram altos na SDI, especialmente na camada de $0-2,5 \mathrm{~cm}$, na qual essa variável diferiu do valor encontrado na camada de 10,0-15,0 cm, com as camadas intermediárias apresentando valores também intermediários (TABELA 5 e Figura 1). No entanto, todos os valores de resistência do solo ao penetrômetro foram altos na SDI, quando comparados ao valor considerado limitante, da ordem de $2,5 \mathrm{~kg} \mathrm{~cm}^{-2}$ (Taylor, 1971). Assim, na camada de $0-2,5 \mathrm{~cm}$ na SDI, a resistência do solo ao penetrômetro foi cerca de seis vezes maior do que o valor limitante, o que indica o alto adensamento do solo na superfície, nesse sistema de manejo. Essa condição de adensamento também foi constatada na camada de 2,5-10,0 cm e, em menor grau, na camada inferior, o que indica um possível comprometimento do crescimento

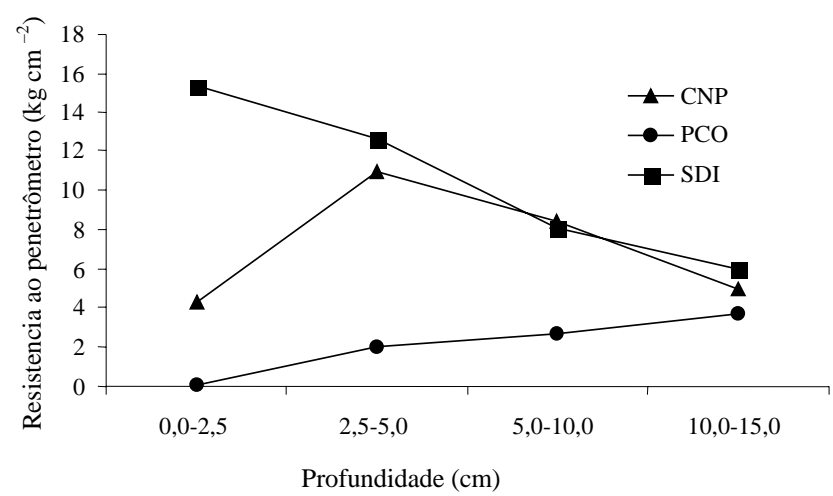

Figura 1- Valores médios de resistência do solo ao penetrômetro, em diferntes profundidades, num Cambissolo Húmico alumínico submetido a três sistemas de manejo: SDI Semeadura direta e PCO - preparo convencional (quatro repetições); e CNP - Campo nativo pastejado (duas repti;cões). 
radicular das plantas nessa camada do perfil do solo, nesse sistema de manejo.

No tratamento CNP, os valores de resistência do solo o penetrômetro foram intermediários aos sistemas de manejo PCO e SDI, sem diferença entre as profundidades estudadas (TABELA 5 e Figura 1). No entanto, todos os valores apresentaram-se superiores ao valor considerado crítico $\left(2,5 \mathrm{~kg} \mathrm{~cm}^{-2}\right)$ para o crescimento radicular da maioria das culturas anuais, explicado pela contínua pressão de pastejo do campo nativo.

Observações visuais, efetuadas durante a coleta das amostras de solo e leitura da resistência do solo ao penetrômetro no campo, permitiram constatar uma melhor distribuição do sistema radicular da cultura de milho (instalada na época sobre o experimento) no perfil do solo no PCO do que naquele na SDI. Assim, um maior volume de radicelas foi constatado no PCO, possivelmente explorando um maior volume de solo do que na SDI. Na SDI, por outro lado, constatou-se uma tendência de concentração da maioria das raízes nas fendas do solo, possivelmente limitando, assim, o volume de solo explorado pela cultura nesse sistema de manejo.

A taxa de infiltração de água no solo, tanto inicial como final, foi maior no PCO, sendo cerca de duas vezes maior do que na SDI e cerca de três vezes maior do que no CNP, na média dos dois momentos (TABELA 6). Tal comportamento pode ser explicado pelo maior volume de macroporos e menor valor de densidade (TABELA 1), constatados por Bertol et al. (2000) neste experimento. No CNP e SDI, Bertol et al. (2000) constataram, neste experimento, baixo volume de macroporos e alto valor de densidade, o que explica, em parte, a sua menor taxa de infiltração de água verificada. Manejos de solo que promovem aumento da densidade, com redução da percentagem de macroporos e/ou da estabilidade de agregados em água, reduzem a taxa de infiltração de água no solo (Dalla Rosa, 1981; Bertol, 1989).

Os valores de taxa de infiltração de água no solo, tanto inicial quanto final, foram altos em todos os tratamentos (Figura 2). Isto é explicado principalmente pelo baixo teor de umidade do solo no momento de realização dos testes de infiltração (TABELA 3), mas, também, pelo método utilizado (cilindros concêntricos), o qual pressupõe uma carga hidráulica ocasionada pela lâmina de água presente sobre o solo durante a execução dos testes de infiltração. Assim, em função da carga hidráulica, as taxas de infiltração apresentadas na tabela 4 e figura 2 podem estar superestimadas em cerca de dez vezes em relação à taxa real de infiltração de água no solo (Forsythe, 1975). A taxa final de infiltração de água no solo prevista para a SDI seria, portanto, $6,7 \mathrm{~mm} \mathrm{~h}^{-1}$, conforme indicado pelo valor da constante de inclinação da curva da equação de regressão utilizada, respeitando o grau de confiabilidade dado polo respectivo coeficiente de regressão. No PCO, por outro lado, a referida taxa seria $30,0 \mathrm{~mm} \mathrm{~h}^{-1}$, o que indica uma substancial diferença entre os dois sistemas de manejo, quanto à essa variável.
TABELA 6 - Valores médios da taxa de infiltração inicial e final de água, num Cambissolo Húmico alumínico submetido a três sistema de manejo do solo em Lages, SC

\begin{tabular}{lccc}
\hline Momento & CNP $^{1}$ & PCO $^{2}$ & SDR \\
\hline & 70 & 194 & 85 \\
Inicial & 9 & 28 & 17 \\
Final & 40 & 111 & 51 \\
\hline Média & & $\mathrm{cm} \mathrm{h}^{-1}-$ & \\
\hline
\end{tabular}

CNP: Campo nativo pastejado; PCO: Preparo convencional; SDI: Semeadura direta.

${ }^{1}$ Média de duas repetições; ${ }^{2}$ média de quatro repetições. 250

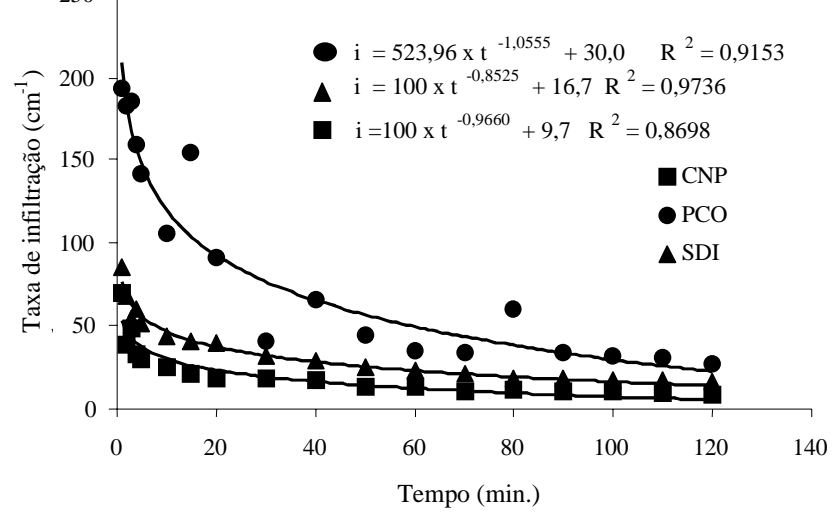

Figura 2 - Taxa de infiltração de água num Cambissolo Húmico alumínio submetido a três sistemas de manejo; PCO Preparo convencional e SDI - Semeadura direta (quatro repetições); e CNP - Campo nativo pastejado (duas repetições)

\section{CONCLUSÕES}

O diâmetro médio ponderado dos agregados estáveis em água varia conforme o sistema de manejo, sendo menor no preparo convencional do que no campo nativo e na semeadura direta, exceto na profundidade de $0-2,5 \mathrm{~cm}$.

A resistência do solo o penetrômetro é maior na semeadura direta do que no campo nativo e preparo convencional, na camada de $0-2,5 \mathrm{~cm}$. Na camada de 2,5-5,0 cm; no entanto, essa variável é maior na semeadura direta e campo nativo do que no preparo convencional.

A taxa de infiltração de água no solo, tanto inicial quanto final, é maior no preparo convencional do que na semeadura direta e campo nativo.

\section{REFERÊNCIAS BIBLIOGRÁFICAS}

BAYER, C.; MIELNICZUK, J. Características químicas do solo afetadas por métodos de preparo e sistemas de cultura. Revista Brasileira de Ciência do Solo, v.21, p.105-112, 1997.

BERTOL, I. Degradação física do solo sob a cultura do alho. Revista Agropecuária Catarinense, v.2, p.47-50, 1989.

BERTOL, I.; COGO, N.P.; LEVIEN, R. Erosão hídrica em diferentes preparos do solo logo após a colheita de milho e trigo, na presença e ausência de resíduos culturais. Revista Brasileira de Ciência do Solo, v.21, p.409-418, 1997. 
BERTOL, I.; SANTOS, J.C.P. Uso do solo e propriedades físicohídricas no Planalto Catarinense. Pesquisa Agropecuária Brasileira, v.30, p.263-267, 1995.

BERTOL, I.; SCHICK, J.; MASSARIOL, J.M.; REIS, E.F. dos; DILLY, L. Propriedades físicas de um Cambissolo Húmico álico afetadas pelo manejo do solo. Ciência Rural, v.30, p.91-95, 2000.

CARPENEDO, V.; MIELNICZUK, J. Estado de agregados e qualidade de agregados de um latossolos roxos, submetidos a diferentes sistemas de manejo. Revista Brasileira de Ciência do Solo, v.14, p.99-105, 1990.

CASTRO FILHO, C.; MUZILLI, O.; PADANOSCHI, A.L. Estabilidade dos agregados e sua relação com o teor de carbono orgânico num Latossolo Roxo distrófico, em função de sistemas de plantio, rotações de culturas e métodos de preparo das amostras. Revista Brasileira de Ciência do Solo, v.22, p.527-538, 1998.

DALLA ROSA, A. Práticas mecânicas e culturais na recuperação de características físicas de solos degradados pelo cultivo no solo Santo Ângelo (Latossolo Roxo Distrófico). Porto Alegre, 1981. 138p. Dissertação (Mestrado) - Faculdade de Agronomia, Universidade Federal do Rio Grande do Sul.

FORSYTHE, W. Física de suelos: manual de laboratório. San José: Internacional de Ciências Agrícolas, 1975. 209p.

KEMPER, W.D.; CHEPIL, W.S. Aggregate stability and size distribution. In: BLACK, C.A. (Ed.) Methods of soil analysis. Madison: ASA, 1965. pt.1, cap.39, p.499-510. (Agronomy, 9)
PHILIP, J.R. The theory of infiltration: IV. Sorptivity and algebraic infiltration equations. Soil Science, v.9, p.257-264, 1957.

SCHICK, J.; BERTOL, I.; BATISTELA, O.; BALBINOT JÚNIOR, A.A. Erosão hídrica em Cambissolo Húmico álico submetido a diferentes sistemas de preparo e cultivo do solo: I. Perdas de solo e água. Revista Brasileira de Ciência do Solo, v.24, p.427-436, 2000.

SILVA, I.F. da; MIELNICZUK, J. Avaliação do estado de agregação do solo afetado pelo uso agrícola. Revista Brasileira de Ciência do Solo, v.21, p.313-319, 1997.

TAYLOR, H.M. Root behavior as affected by soil structure and strength. In: CARSON, E.W. (Ed.) The plant root and its envoronment. Virginia: Virginia Polytechnic and State University, 1971. cap.11, p.271-291.

TISDALL, J.M.; OADES, J.M. The management of ryegrass to stabilize aggregates of a red-brown earth. Australian Journal of Soil Research, v.18, p.415-422, 1980.

YODER, R.E. A direct methodo of aggregate analysis of soils and a study of the physical nature of erosion losses. Journal of the American Society of Agronomy, v.28, p.337-351, 1936.

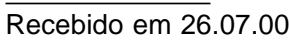

